\title{
Population Health Research: Early Description of the Organizational Shift Toward Population Health Management and Defining a Vision for Leadership.
}

\author{
Kristi L. Caldararo \\ Thomas Jefferson University \\ David B. Nash \\ Thomas Jefferson University
}

Follow this and additional works at: https://jdc.jefferson.edu/healthpolicyfaculty

Part of the Public Health Commons

Let us know how access to this document benefits you

\section{Recommended Citation \\ Caldararo, Kristi L. and Nash, David B., "Population Health Research: Early Description of the Organizational Shift Toward Population Health Management and Defining a Vision for Leadership." (2017). College of Population Health Faculty Papers. Paper 79. \\ https://jdc.jefferson.edu/healthpolicyfaculty/79}

This Article is brought to you for free and open access by the Jefferson Digital Commons. The Jefferson Digital Commons is a service of Thomas Jefferson University's Center for Teaching and Learning (CTL). The Commons is a showcase for Jefferson books and journals, peer-reviewed scholarly publications, unique historical collections from the University archives, and teaching tools. The Jefferson Digital Commons allows researchers and interested readers anywhere in the world to learn about and keep up to date with Jefferson scholarship. This article has been accepted for inclusion in College of Population Health Faculty Papers by an authorized administrator of the Jefferson Digital Commons. For more information, please contact: JeffersonDigitalCommons@jefferson.edu. 
Population Health Research: Early Description of the Organizational Shift toward Population Health Management and Defining a Vision for Leadership

\section{Authors:}

Kristi L Caldararo, M.H.A. (Corresponding Author)

Thomas Jefferson University Hospitals

Associate Administrator, Clinical Services

833 Chestnut Suite 610

Philadelphia, PA 19107

215-955-6546 | Kristi.Caldararo@jefferson.edu

David B Nash, M.D., M.B.A.

Thomas Jefferson University Hospitals

Dean, Jefferson College of Population Health

901 Walnut Street, $10^{\text {th }}$ Floor

Philadelphia PA, 19107

215-955-6969 | David.Nash@jefferson.edu 
Declaration of Conflict of Interest: The authors declare that there is no conflict of interest. 


\section{Abstract}

As healthcare delivery systems adapt to the changing marketplace, many struggle to define a clear strategy that will prove successful in managing the health of entire populations. The federal government continues to put increasing pressure on organizations to shift away from the traditional way of delivering episodic care and move toward managing populations as a whole, before, during, and after a patient presents in a healthcare facility. Private payers have begun to follow suit as risk based payer contracts and bundled payment models become increasingly popular. For organizations to adequately influence the health outcomes of a population, they must be responsible for more than just a patient's medical care. They must partner with the community to create a strategy that encompasses the psychosocial and environmental factors that contribute to one's health.

Although healthcare leaders know this industry transformation is imminent, there is minimal research that shares best practices in regard to designing and implementing a successful population health management strategy. Interviews were conducted with leadership from 10 organizations in order to understand the strategic approach taken by delivery systems and healthcare institutions that view population health as a key aspect of their overall mission. Responses were recorded and outlined in a detailed response grid. The objective is to provide a qualitative overview of how industry leaders are currently responding to population health. Additionally, common themes and recommendations are presented to serve as guidance for other healthcare organizations that are at the start of their journey toward population health management. 


\section{Introduction}

As the shift from fee-for-service to value-based care continues to unfold, healthcare systems are changing the way they deliver care. In 2010, when the Affordable Care Act (ACA) was signed into law, a myriad of expectations were put forth on healthcare delivery systems that encouraged responsibility for the health of patients beyond the four walls of the hospital. The ACA promotes attention to quality and shifts the focus away from volume, which has been the historical driver of revenue for over two and a half centuries. This shift in focus allows for delivery systems to take a more proactive role in the community and to create multifaceted partnerships with local and regional community based organizations, schools, insurance companies, legislative bodies, businesses, public health agencies, and others to identify and solve problems that contribute to poor health. ${ }^{1}$ Although health care organizations now have a significant opportunity to transform the health of the population they serve, many are struggling to manage this transition from a governance, cultural, and operational perspective. Nevertheless, adopting an organized population health approach to care that encompasses the wide array of the personal, social, economic, and environmental determinants of health is essential for care delivery systems to thrive in today's dynamic healthcare landscape.

\section{Methods}

\section{Study Design}

Qualitative data was collected from structured interviews that were conducted with leaders and executives from 10 U.S. health care organizations, primarily not-for-profit 
health care delivery systems. All interviews were conducted using a standard set of questions. Interviews averaged about 45 minutes in duration. Additional time was allotted to encourage free-flowing conversation and flexibility in responses. The interview questions were designed to promote discussion around how organizations are embracing population health demands and methodologies.

\section{Participants}

Interview participants consist of leaders with varying titles and experience and currently work in organizations that are at the forefront of population health management. Participant organizations include 8 not-for-profit healthcare delivery systems, 7 of which are academic medical centers. Additionally, leadership from one population health institute and one health services research center were interviewed. A full list of organizations interviewed are as follows: Atlantic Health System, University of Wisconsin - Population Health Institute, University of North Carolina Chapel Hill, Vanderbilt University Medical Center, Stony Brook Medicine, Trinity Health, Montefiore Medical Center, Dartmouth-Hitchcock Medical Center, Temple University Health, and Kennedy Health. Supplemental Table S1, available online, lists additional information on each interviewee including organization name, participant name, and job title.

\section{Responses}

Interview responses, as shown in Table 1, were analyzed and organized in accordance with industry trends and common themes.

\section{Key Themes \& Recommendations}

Of the leaders that were interviewed, many of them pursued different career paths, hold different titles within their organization, and have different scopes of responsibility. 
However, when asked the interview questions about population health, common themes clearly emerged from all parties. That said, there is no clear cut path to success. Many organizations have differing strategies and approaches to population health, but in all cases, interviewees agreed that value based care and population health management is here to stay. Key themes and recommendations are discussed in order to provide a vision for the future and give readers an understanding of how leaders in this industry perceive and adapt to the change in healthcare trends.

1. Accept where the market is heading.

Population health management is a vital strategy necessary in order be successful in the new world of quality focused care delivery. As the market continues to consolidate and standalone practices and institutions become less prevalent, separate entities are going to have to work together toward a common goal.

By the end of calendar year 2016, 30\% of Medicare payments will be tied to alternative payment mechanisms (APMs) such as patient-centered medical homes, ACOs, and bundled payments. Additionally, the Department of Health and Human Services predicted that in 2018, half of Medicare payments will go to APMs. The private sector is also onboard. By 2020, nearly 20 leading health insurers and provider groups stated a commitment to allocating $75 \%$ of their business into valuebased arrangements. ${ }^{2}$

Yesterday's era of managed care consists of scarce access, long wait times, mandatory referrals to see a specialist, tightly controlled narrow networks and limited patient choice. The present and expanding era of care management features online 
scheduling, walk in appointments, e-visits, self-referrals, patient portals, and encouragement to remain in-network. ${ }^{3}$ The majority of organizations are currently somewhere in-between these two eras. For organizations that are stuck in yesterday's era, this resistance to change will prove fatal to its longevity in the market.

2. Do not turn the focus away from internal operations.

Often times when population health is mentioned, the overwhelming pressure to care for entire communities yields the urge to immediately place an immense focus on community organizations and outpatient facilities. Population health management should be considered a partnership between the inpatient and outpatient settings. As important as it is to focus on outreach and community benefit, a similar focus still must be on inpatient operations. In order to begin and foster a productive relationship, the community organization must trust that when patients are in the inpatient setting, they are receiving the best quality care.

Many of the interviewees spoke of the disconnect between their organization's inpatient and outpatient strategy, vision, and execution style. It is important for leadership from each area to communicate and share information amongst each other and with population health personnel, should that person(s) reside outside inpatient and outpatient leadership.

Essential improvement initiatives prevalent in many institutions today such as readmission management, timely discharge, and effective post-acute strategy all bridge into the outpatient setting. For example, developing strategies to shift high-risk patients away from high cost episodic care and into a primary care setting, where 
their disease can be proactively managed as an outpatient, will ultimately reduce ED utilization and avoidable readmissions. Both inpatient and outpatient leadership must collaborate to make such initiatives successful. Involving and empowering physicians in clinical initiatives and protocol development will help to close care gaps and disseminate a uniform strategy across the care continuum.

In accordance with the changing healthcare landscape, it is no secret that internal operations are also undergoing a necessary shift. Care givers are being deployed outside of the acute care setting, medical visits are completed using e-visits and telehealth, urgent care centers are decompressing emergency departments, and hospitals are closing units and downsizing the number of inpatient beds. Healthcare delivery systems must keep internal operations embedded in strategy as they work to transform the business toward a new model of care and invest in infrastructure that will improve access and community health.

3. Gauge the appetite for taking on risk.

According to a 2016 Modern Healthcare Hospital Systems Survey, only 13 hospital systems out of 80 respondents reported they derived $10 \%$ or more of their net patient revenue in 2015 from risk-based contracts. ${ }^{4}$ Today, hospitals are apprehensive to take on risk based contracts for multiple reasons including data sharing barriers and impact on financial performance. Risked based contracts can range from more aggressive full-risk strategies such as capitation, to lesser-risk contracts such as bundled payments. Not all organizations have the same capacity to take on risk; therefore, an organizational risk-bearing plan should be developed to limit financial downside risk. 
Considering hybrid models that emphasize cost containment while putting an equal focus on quality and outcomes have become increasingly popular.

In 2017, organizations that participate in Medicare part B, will begin to choose one of two paths offered by the Quality Payment Program, the first track being the MeritBased Incentive Payment System (MIPS) and the second being Advanced Alternative Payment Model (APM). MIPS focuses primarily on managing penalties, whereas APMS focus more on managing risk. Payment adjustments for the Quality Payment Program go into effect on January 1, 2019. ${ }^{5}$ These programs reiterate the powerful message that change is inevitable and that quality is now tied to actual dollars. Organizations need to bring together key personnel from the acute care hospital, outpatient setting, accountable care organization, clinically integrated network, and others to make educated and informed decisions regarding financial risk which will ultimately determine the long term stability of the health care institution.

4. Invest in information technology infrastructure.

In order to successfully follow a patient through the continuum of care, a robust information technology (IT) infrastructure is necessary. The Health Information Technology for Economic and Clinical Health Act, signed into law in 2009, jumpstarted the meaningful use program where organizations were incentivized to adopt a certified electronic health record (EHR) system. As of 2015, 96\% of all non-federal acute care hospitals possessed a certified health IT system and these numbers continue to grow. ${ }^{6}$ 
Organizations must be willing to invest the time, training, and financial resources in an IT solution that will aim to achieve an advanced level of interoperability which reduces clinical variation and unstandardized documentation. Relevant and actionable information is imperative to improving population health. Sophisticated IT solutions will aid in converting the overwhelming abundance of data available in current systems and produce a concise and useful set of information. This information will allow for providers to make informed clinical decisions and redesign the way care is delivered. What will begin to set organizations apart moving forward is what they do with the wealth of information they now have access to and how they execute strategy backed by data.

The ongoing gathering and analysis of patient health information is the key to providing proactive and preventative care that will ultimately keep patients out of the hospital, where they can be managed in a lower cost care setting. As the market consolidates, health systems are partnering together to share resources and promote stability in this uncertain time. An ideal IT solution aims to create a system that is centered on the patient, not the individual organization. As a patient travels throughout a large health system or across many different health systems, an electronic solution that can follow the patient through different organizations is critical to understanding the entirety of the patient's medical and psychosocial history. While health care systems are still on disparate EHR systems, the sharing of information across institutions can help to manually fill some of the care gaps until a permanent solution is in place. Due to the large financial burden associated with planning for, adopting, and implementing a new IT solution, it is becoming less 
realistic for a health system, especially one actively acquiring new partners and businesses, to have all of its entities be on a single vendor EHR system. An alternative and more financially realistic solution is for organizations to focus on establishing a robust data warehouse and health information exchange platform in order to have direct linkage to varying EHR systems.

5. Create and communicate a focused strategy.

There was unanimous consensus among the interviewees that incorporating population health management into organizational strategy is of utmost importance. Population health management is still a new and ambiguously defined term for healthcare leaders. There are many modifications that must be made, operational, financial, and cultural, that come with building a population health management strategy. Leaders need to encourage and support change at the highest level and then disseminate the vision to all levels of the organization.

Focus is imperative when developing a strategy. Many organizations regret trying to take on too much too soon and fail as a result. Taking on an overwhelming set of tasks that encompass every facet of population health is unrealistic and unattainable. Well defined and measurable goals should be created and monitored on a regular basis. Population health management will not happen overnight; it takes time, resources, and teamwork to build a cohesive strategy. Leadership should decide where the organization is going to focus and communicate that to providers and staff across the continuum. If everyone is working toward an understood common goal, it 
will make investment decisions in relation to services, capital, and technology less controversial.

Additionally, it is important to make the organization known in the industry and as a leader in this arena. Physicians, patients, administrators, and community members, recognize this fundamental market shift toward value. A health care delivery system will have a tough time getting patients to choose their organization for their care and will struggle with attracting the talent they need if they are not known for truly caring for the entire population they serve.

\section{Conclusions}

Healthcare delivery systems are adapting to the significant remodeling of the industry, which drastically alters the way organizations deliver care and are reimbursed. Organizations across the country tell the story of a heterogeneity of infrastructures and strategies related to population health management. Care management goals and community health strategies will vary by organization. It is important to understand that although there are common themes among organizations investing in population health, an individualized approach should be taken based on the needs of the patient population and the financial and operational capabilities that the institution has to offer.

The ultimate goal is for leaders to proactively predict market shifts and begin to set the stage for future healthcare delivery. However, in reality, the overwhelming majority of healthcare organizations are reacting to federal and private demands in order to remain financially and operationally viable in the marketplace. There is still an overwhelming 
amount of uncertainty in this new care model, but there is room for creativity, teamwork, and collaboration across many different channels.

The ideal framework for population health management is not black and white; however, there are key elements that are imperative to a successful strategy and implementation plan. Organizations can tailor individual aspects to their organization, but should keep in mind that standardization where appropriate will allow for adequate information sharing and appropriate benchmarking. As organizations continue to shape their vision in relation to population health, it is in their best interest to make the aforementioned themes top priority.

\section{Reprint requests should be directed to:}

\section{Kristi L Caldararo, M.H.A. (Corresponding Author)}

Thomas Jefferson University Hospitals

Associate Administrator, Clinical Services

833 Chestnut Suite 610

Philadelphia, PA 19107

215-955-6546 | Kristi.Caldararo@jefferson.edu 


\section{References}

1. Institute of Medicine. (2014). Population health implications of the Affordable Care Act: Workshop summary. Washington, DC: The National Academies Press. Retrieved on August 15, 2016 from https://www.nap.edu/catalog/18546/population-healthimplications-of-the-affordable-care-act-workshop-summary

2. Watson Health, I. (2015, July). Financing provider-led population health management with new value-based incentives. Thought Leadership White Paper. Retrieved on August 20, 2016 from https://www.ibm.com/web/wcm/connect/watson/6d59a35fcff7-4978-88be-

\section{5ff1bb83e04/HPW03008USEN.PDF?MOD=AJPERES\&CVID=lt5YdhB}

3. Advisory Board, H. (2013). Playbook for Population Health. The Advisory Board Company. Retrieved on September 1, 2016 from https://www.advisory.com/ /media/Advisory-com/Research/HCAB/ResearchStudy/2013/Playbook-for-Population-Health/Playbook-for-Population-Health.pdf

4. Modern Healthcare. (2016, June). Under construction: risk-based reimbursement. Retrieved on September 2, 2016 from http://www.modernhealthcare.com/article/20160618/MAGAZINE/306189982

5. Quality Payment Program. (2015). Modernizing Medicare to provide better care and smaller spending for a healthier America. Retrieved on September 18, 2016 from https://qpp.cms.gov/

6. The Office of the National Coordinator for Health Information Technology (2015). Health IT dashboard: percent of hospitals, by type, that possess certified health IT. Retrieved on October 2, 2016 from 
http://dashboard.healthit.gov/quickstats/pages/certified-electronic-health-recordtechnology-in-hospitals.php 